\title{
Configurações
}

Revista de sociologia

\section{O envolvimento dos moradores nos programas de realojamento no Portugal democrático}

The involvement of residents in resettlement programmes in democratic

Portugal

La participation des résidents aux programme de réinstallation dans les sociétés

démocratiques du Portugal

\section{Camila Rodrigues}

\section{OpenEdition}

\section{Journals}

\section{Edição electrónica}

URL: http://journals.openedition.org/configuracoes/1181

DOI: 10.4000/configuracoes. 1181

ISSN: 2182-7419

\section{Editora}

Centro de Investigação em Ciências Sociais

\section{Edição impressa}

Data de publição: 30 Junho 2012

Paginação: 181-193

ISSN: 1646-5075

Refêrencia eletrónica

Camila Rodrigues, « $O$ envolvimento dos moradores nos programas de realojamento no Portugal democrático ", Configurações [Online], 9 | 2012, posto online no dia 27 novembro 2013, consultado o 30 abril 2019. URL : http://journals.openedition.org/configuracoes/1181 ; DOI : 10.4000/ configuracoes. 1181

Este documento foi criado de forma automática no dia 30 Abril 2019.

(c) CICS 


\section{O envolvimento dos moradores nos programas de realojamento no Portugal democrático}

The involvement of residents in resettlement programmes in democratic

Portugal

La participation des résidents aux programme de réinstallation dans les sociétés démocratiques du Portugal

\section{Camila Rodrigues}

\section{Introdução}

1 Durante o Estado Novo, o apoio às populações carenciadas era remetido para as instituições de solidariedade social e, ao nível habitacional, a solução passava essencialmente pela construção clandestina. Os programas de habitação social assumiam uma dimensão disciplinadora e eram direccionados para grupos sociais que preenchiam requisitos favoráveis à promoção dos valores morais do regime (Gros, 1994). As políticas habitacionais reflectiam o controlo social exercido sobre a população: as áreas centrais das principais cidades não estavam ao alcance das classes operárias, que eram remetidas para bairros periféricos, o que obstava à sua concentração e respectivos perigos para a estabilidade governativa (Queirós, 2007).

2 A revolução de abril de 1974 originou uma nova era na política de habitação social que implicou o planeamento urbano em colaboração com os moradores, mediante o incentivo à participação popular ao nível da gestão e controlo dos programas de realojamento. $\mathrm{O}$ Estado dotou os moradores de poder decisório e executivo e concedeu-lhes recursos materiais que lhes permitiu participar efectivamente na escolha dos terrenos para construção, das tipologias das casas, das infra-estruturas dos bairros e na sua edificação. Num processo de reforço mútuo, as oportunidades políticas e os recursos organizacionais 
disponibilizados motivaram a auto-organização dos moradores, que sentiam directamente o impacto da sua própria acção na melhoria das suas condições de vida.

Estas forças causais emergiram e conjugaram-se durante o Processo Revolucionário em Curso (PREC), entendido enquanto conjuntura crítica que se caracterizou por uma fragilidade intrínseca do Estado: coexistiam ao nível do próprio Estado dois centros de poder antagónicos, um «burguês» e outro «popular», que originaram uma dualidade institucional e, consequentemente, uma paralisia administrativa. Esta «dualidade de impotências» (Santos, 1984) foi marcada pela resistência da administração pública tradicional ao processo de democratização e pela consequente criação, no seio estatal, de entidades paralelas, menos burocratizadas e mais favoráveis à democracia, que procuravam responder às solicitações dos movimentos sociais de cariz popular. Esta divisão no interior do sistema político determinou uma maior vulnerabilidade do Estado aos movimentos sociais, que representavam uma ameaça efectiva para a governação ao forjarem alianças de consciência ou interesse com elementos tanto no interior como no exterior do próprio sistema, sobre o qual exerciam pressão (McAdam et al., 2009). Foi deste contexto excepcional que emergiu, como resultado divergente, um forte envolvimento dos moradores nos programas de realojamento.

O término da fase de transição democrática concretizou-se com a aprovação da Constituição em Abril de 1976, a qual determinou uma maior estabilidade governativa e o reforço do poder estatal. A Constituição consagrou mecanismos de democracia participativa que visaram contribuir para a qualidade da democracia representativa, mediante a promoção do acesso dos cidadãos aos processos políticos para além do momento eleitoral. No entanto, dados empíricos recolhidos até ao momento permitem constatar que, ao nível político-institucional, os programas de realojamento que pressupunham um forte envolvimento dos moradores foram suspensos e gradualmente substituídos por programas que assumiam uma abordagem de carácter.

5 A adesão de Portugal à Comunidade Económica Europeia (CEE) colocou o país sob o efeito da europeização. Ao nível das políticas sociais e de realojamento fez-se sentir a influência dos Programas Europeus de Luta Contra a Pobreza (PELCP), que de forma gradual foram promovendo uma lógica de actuação que prescrevia a promoção da «cidadania activa», o que passava pelo envolvimento das populações alvo nos programas que as abrangiam. Esta tendência acentuou-se com os Planos Nacionais de Acção para a Inclusão (PNAIs), que operacionalizaram as políticas de inclusão social comunitárias durante a década de 2000, e mantém-se na presente década, com a Estratégia Europa 2020 e os Planos Nacionais de Reforma: a «activação da participação» passou a figurar como um elemento legitimador da intervenção social.

6 As pressões comunitárias vão ter reflexo nas políticas sociais e nos programas de realojamento. Apesar de manterem uma abordagem marcadamente estatizada, a crescente articulação com as políticas de combate à exclusão social tem vindo a promover a implementação de projectos de intervenção social nos bairros. A responsabilidade pela execução destes projectos é delegada, essencialmente, nas organizações de solidariedade social, que além de prestarem apoio directo às populações carenciadas e representarem os seus interesses junto do poder local e central, assumem um claro papel socializador. A formação em competências pessoais e o apoio ao associativismo surgem como acções a implementar por via dos projectos. O tipo de envolvimento proposto não implica a transferência efectiva de poder e recursos para os moradores mas sim a sua mobilização para acções devidamente enquadradas ao nível políticoadministrativo, geralmente de 
carácter lúdico-recreativo ou relacionadas com a manutenção das habitações e espaços comuns.

7 Este tipo de envolvimento contrasta fortemente com o verificado no pós 25 de Abril. Deriva de um contexto diverso, serve objectivos distintos e gera efeitos divergentes no sistema governativo em que se insere. Entre aquele momento inicial e o presente ocorreu um processo transformativo e é esta variação, aqui descrita sucintamente, que assume interesse científico e que propomos analisar no presente artigo: os diversos contextos sociais, enquadramentos jurídicos, dinâmicas relacionais e actores envolvidos produzem uma variedade cientificamente interessante de intensidades e formas de envolvimento que constituirá o nosso objecto.

\section{Os programas de realojamento no Portugal democrático}

8 A revolução de Abril favoreceu a emergência de novos poderes e a intensidade dos movimentos sociais e populares. Foi neste contexto que surgiu o Programa SAAL (Serviço de Apoio Ambulatório Local), por Despacho do Ministério da Administração Interna e do Ministério do Equipamento Social do Ambiente de 31 de julho de 1974, com o objectivo de facultar apoio financeiro e técnico aos moradores na melhoria das suas habitações e respectivas infraestruturas, numa lógica de intervenção marcada pela coresponsabilização e auto-organização. O Despacho de 6 de agosto de 1974 definia-o como um "corpo técnico especializado que deverá apoiar, através das Câmaras Municipais, as iniciativas de populações mal alojadas no sentido de colaborarem na transformação dos próprios bairros, investindo os próprios recursos latentes e, eventualmente, monetários".

Este corpo técnico de especialistas, que incluía arquitectos, assistentes sociais, sociólogos, engenheiros, juristas e estudantes, articulava-se directamente com os moradores autoorganizados que participavam activa e intensamente na discussão e escolha das tipologias das casas, equipamentos, locais e planos urbanísticos dos novos bairros ${ }^{1}$ :

Em 1974, a revolução de Abril trouxe algumas oportunidades, principalmente no meu caso e de outros jovens que na altura tínhamos 23-24 anos, cansados de viver em barracas depressa nos organizámos e constituímos uma comissão de moradores. Depois mais tarde essa comissão de moradores o que pretendia era acabar com as barracas, mas ao abrigo da legislação uma comissão de moradores não tinha poderes para construir a habitação, constituímos uma associação que foi legalmente e estatutariamente o que nos deu a oportunidade de avançar com o processo das casas. Apresentámos os estatutos, o projecto, reunimos com a Câmara e com a Junta de Freguesia, apresentámos o que nós pretendíamos, fomos bem acolhidos e depressa nos deram força e ânimo para continuar. Isto depois teve a ajuda de uma equipa SAAL que vinha do Fundo de Fomento à Habitação que era a parte técnica que nos dava o apoio, a Câmara Municipal doou-nos o terreno com direito de superfície por 70 anos e pagou as infra-estruturas na construção. Nós pedimos dinheiro ao Fundo de Fomento à Habitação com juros a 3\% na altura e deitámos mão à obra e começámos a construir. (Excerto de entrevista a secretário de cooperativa habitacional de bairro SAAL/ PER, 2010)

O fim da conjuntura crítica reflectiu-se na política habitacional pelo bloqueio do SAAL, que foi praticamente anulado por Despacho do I Governo Constitucional, de 27 de Outubro de 1976, que conferia às Câmaras Municipais o controlo das operações então em curso e assim o condenava implicitamente, se não explicitamente, à extinção. O Despacho reflecte, de forma inequívoca, a retirada de protagonismo aos moradores auto- 
organizados e equipas técnicas que os apoiavam, que eram acusados de transcender as incumbências que lhes haviam sido atribuídas e de actuar à margem das entidades estatais: "algumas brigadas SAAL se desviaram, de forma evidente, do espírito do despacho que as mandava organizar, actuando à margem do Fundo Fomento de Habitação (FFH) e das próprias autarquias locais"... "às Câmaras Municipais não foi facultada a possibilidade do seu contributo, nem ao FFH foi solicitada a ajuda técnica conveniente para este tipo de operações, nem os terrenos se conseguiram com a celeridade que o processo impunha, nem o número de fogos construídos até esta data tem qualquer significado". Apesar destas críticas, aquando da saída do Despacho estavam em actividade 169 operações em todo o país, abrangendo 41665 famílias. Estavam em processo de construção 2259 fogos e o arranque de mais 5741 estava iminente.

11 A inviabilização dos Programas SAAL e a ausência de respostas alternativas por parte do poder central motivou as Câmaras Municipais e Juntas de Freguesia a desenvolverem programas de Auto-construção e Auto-acabamento, de forma a dar resposta urgente à pressão dos cidadãos em situação de precariedade habitacional. Os programas de Autoconstrução implicavam uma contratação entre as famílias abrangidas e a autarquia. 0 contrato previa a cedência de lotes municipais em direito de superfície às associações de moradores, a disponibilização de projectos-tipo de habitação, o fornecimento gratuito dos materiais de construção e apoio técnico e social. Os moradores forneciam a mão-de-obra e os materiais destinados ao interior das habitações e responsabilizavam-se pela demolição da sua barraca. Nos programas de Auto-acabamento a Câmara Municipal assegurava a construção da habitação e o morador responsabilizava-se pela conclusão dos interiores, sendo as habitações cedidas em regime de arrendamento social.

12 No entanto, os programas de realojamento que surgiram desde então apresentam um carácter estatizado que concebe e produz a habitação social independentemente dos recursos dos moradores abrangidos. Foi o caso do Plano de Intervenção a Médio Prazo (PIMP), criado pelo Decreto-lei 226/87 de 6 de junho, que visava o realojamento de indivíduos que se encontravam a residir em terrenos destinados à construção de infraestruturas rodoviárias, como a CRIL e o Eixo Norte-Sul, e deu origem a alguns dos maiores bairros sociais da capital, como o Bairro Padre Cruz ou Chelas. Tendo abrangido a construção de 9698 fogos até ao ano de 1993, o PIMP beneficiou de fundos comunitários direccionados para a reabilitação urbana e evidenciou a prevalência da lógica quantitativa em detrimento de uma abordagem holística ao problema habitacional (Ferreira, 1988).

Seguiu-se o Programa Especial de Realojamento nas Áreas Metropolitanas de Lisboa e Porto (PER), criado através do Decreto-Lei $\mathrm{n}^{\circ}$ 163/93, de 7 de maio, que se caracterizou por uma abordagem burocratizada que pressupunha a construção massiva para realojar populações multi-problemáticas e economicamente vulneráveis (Ferreira, 1994). O PER encerrou três ideias fundamentais: a erradicação das barracas; o envolvimento dos municípios; e a alteração de estilos de vida associados aos bairros degradados através do realojamento (Cachado, 2009). Os processos de realojamento no âmbito do PER envolveram o recenseamento prévio das populações a alojar, com anos de desfasamento entre o recenseamento e o alojamento, sem que estas populações tivessem um envolvimento assinalável no processo (Guerra, 1994):

Com a criação da associação de moradores e a cooperativa, a nossa política era alojar os moradores do Bairro. Uma vez que os mais velhos já tinham habitação, nós queríamos dar continuidade com os fi lhos, para não deixar que os filhos dos moradores mais velhos fossem morar para outro lado. Isso não foi conseguido, houve outras construções feitas neste caso pela Câmara Municipal e a Câmara Municipal, com legitimidade porque as casas foram construídas por eles, atribuiu as 
casas a outras pessoas vindas de outros lados"... "Havia e há pessoas que tiveram que sair daqui do bairro, foram viver para outros lados porque não conseguiram aqui apanhar casa, que tiveram que partir enquanto vieram outros de outros lados para cá"... "Em termos da cooperativa nós não acompanhámos a evolução disso porque a Câmara nunca nos solicitou para nós trabalharmos em parceria, portanto não acompanhei bem qual foi o critério, embora nós tivéssemos manifestado alguns desacordos e houve aqui algumas situações em que a cooperativa fez chegar à Câmara Municipal o desagrado, o descontentamento com a forma como estava a ser feito o realojamento no Bairro e a Câmara o que nos respondeu foi que ela é que era a dona da obra e como tal é que tinha poderes para pôr aqui fosse quem fosse e nós aí ficámos simplesmente pelo protesto e pelo descontentamento. (Excerto de entrevista a secretário de cooperativa habitacional de bairro SAAL/ PER, 2010)

Em 2004, o PER deu lugar ao PROHABITA, instituído pelo Decreto-lei 135/2004 de 3 de junho, o qual procurou colmatar algumas limitações verificadas aquando da implementação do seu antecessor: apresenta uma visão mais lata da noção de carência de habitação, que deixa de estar restringida às barracas e passa a incluir uma maior diversidade de situações de desadequação habitacional; é um programa aberto em regime de continuidade que abrange todo o território nacional; pressupõe uma relação contratual entre os poderes central e local e a articulação com outras políticas urbanas, tais como o incentivo ao arrendamento. Apesar destas inovações, o PROHABITA está em consonância com o seu antecessor quanto ao seu carácter tendencialmente estatizado.

15 A par da evolução político-legislativa, que veio a favorecer uma intervenção estatizada em detrimento de uma abordagem participativa às políticas públicas de realojamento, outros factores poderão ter contribuído para a relativa "saída de cena" das organizações de moradores, como a ausência de um historial de prática participativa que favorecesse o seu enraizamento e perpetuação para além do objectivo concreto de acesso directo e imediato à habitação: uma vez satisfeitas as reivindicações, os moradores desmobilizam, individualizam-se e o movimento que os uniu em torno de um objectivo comum perde razão de ser (Vilaça, 1994).

\section{A intervenção habitacional e social perante o paradoxo da participação}

16 A ausência de envolvimento dos moradores nos programas que os envolvem é difícil de legitimar numa sociedade democrática, particularmente quando esta se encontra sob o efeito da europeização. Este facto justifica o desenvolvimento de estratégias participativas que irão influir na dinâmica dos bairros. A adesão de Portugal à Comunidade Económica Europeia (CEE) submeteu as políticas sociais às contingências comunitárias. Os Programas e Estratégias Europeus de combate à exclusão social substituem gradualmente a noção de pobreza pelo conceito de exclusão social, fenómeno multidimensional que comporta a astenia participativa, e prescrevem o envolvimento activo dos destinatários das políticas sociais no seu próprio «processo de inserção» de forma a combater o «assistencialismo» pelo empoderamento (empowerment), entendido enquanto «capacidade de gerir a própria mudança» (Bureau Internacional do Trabalho, 2003).

17 As organizações de solidariedade social surgem como agentes de socialização a intervir directamente nos bairros, e além de prestarem apoio directo no alívio de situações de carência, desenvolvem projectos que incluem programas formativos que visam promover 
a capacitação comunitária através da dinamização do associativismo e da formação em competência pessoais. É o caso dos Contratos Locais de Desenvolvimento Social (CLDS), que apresentam como um dos seus eixos de acção a «capacitação da Comunidade e das Instituições» através do «desenvolvimento de acções que apoiem a auto-organização dos habitantes».

A activação da participação numa lógica de cima para baixo (up-bottom) pressupõe essencialmente a dinamização de associações que defendam fins coincidentes com os do Estado e seus aliados, que visam a promoção do consenso social. A ausência de espontaneidade e objectivos próprios na constituição destas associações pode originar a reprodução, mesmo que incauta, do discurso dominante, bem como a dependência dos seus mobilizadores, levando a questionar se a sua criação serve os objectivos, interesses e necessidades dos seus membros ou dos técnicos, organizações e projectos que têm como missão a sua criação:

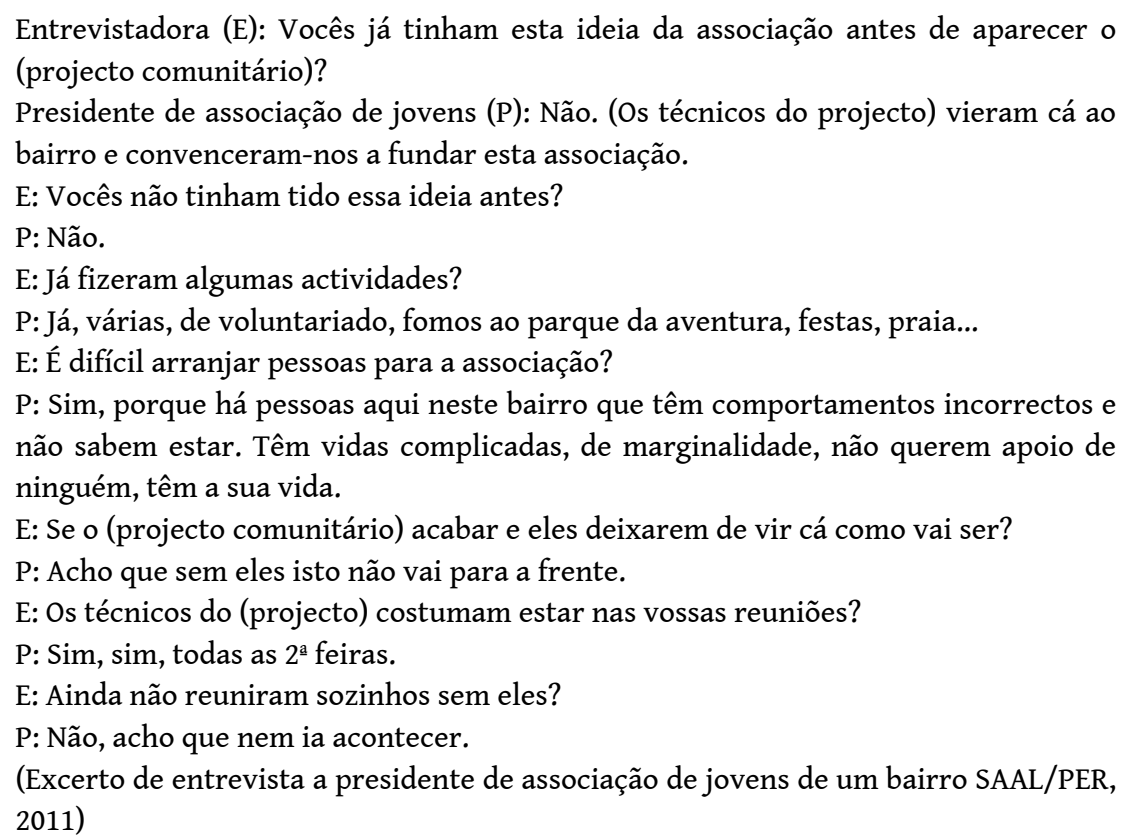

Estamos perante a dicotomia participação/mobilização (Sartori, 2009): a participação é entendida enquanto auto-movimentação de cidadãos livres que agem e intervêm em função da sua própria vontade; a mobilização pressupõe uma colectividade passiva e influenciável que é colocada em acção por entidades externas. Os indivíduos participam mas não mobilizam, são mobilizados. Enquanto a participação está associada à experiência democrática, a mobilização resulta de terminologia de tipo militarista introduzida no vocabulário político através dos partidos milicianos e da experiência do totalitarismo. Apesar da sua origem, é um termo comummente aplicado à governação democrática, mas não sem consequências.

No caso dos programas de realojamento de tipo participativo, os moradores autoorganizados assumem um papel preponderante num momento em que um Estado fragilizado lida com eles de forma mais equilibrada, no que se refere à divisão de poderes. No caso dos programas de habitação de carácter estatizado, os moradores destituídos de poder decisório e executivo recebem a chave na mão e são alojados em bairros onde posteriormente as organizações de moradores convivem com as organizações de solidariedade social, e é essencialmente a estas que cabe a prestação de apoio directo à 
população e a «activação da sua participação», com um duplo objectivo de redução de riscos e controlo social:

Eu acredito neste tipo de projectos, senão não estaria a trabalhar neles, mas são projectos com uma acção a médio-longo prazo, e eu digo que deviam quase ser utilizados como paliativos" ... "redução de riscos, de sofrimento, de conflitos sociais, uma forma de o Estado manter todo um conjunto populacional menos tenso, mais tranquilo" ...."a quantidade de vezes que as pessoas vêm aqui completamente exasperadas e revoltadas e queixam-se em relação à Câmara Municipal, à Segurança Social, à polícia, o que for, descarregam aqui tudo connosco e quando saem daqui já saem mais aliviadas e já não vão ali para a porta do outro serviço atirar pedras chamar nomes ao senhor juiz. Portanto é uma forma de atenuar. (Excerto de entrevista a coordenadora de projecto comunitário, 2011)

21 A relevância atribuída às organizações da sociedade civil coloca a questão da sua própria democraticidade, nomeadamente ao nível da divisão interna de poderes, e obriga a questionar o altruísmo que advogam. Se é a estas organizações que o Estado atribui o papel de agentes de socialização, configurado pela atribuição de responsabilidades no desenvolvimento do espírito cívico e participativo das camadas mais desfavorecidas da sociedade, nas quais se incluem os moradores dos bairros de realojamento, é imperativo considerar a sua legitimidade para exercer esta função, entendida enquanto adequação aos próprios princípios que professam.

O estudo «ONGs de solidariedade social: práticas e disposições» (1995) refere a prevalência de um forte personalismo nestas entidades, que apresentam uma considerável dependência da iniciativa e carácter dos seus líderes. Os dirigentes das ONGs afirmam a sua filiação a princípios democráticos de abertura e participação, os quais são fundamentais para o reconhecimento da legitimidade das suas organizações numa sociedade democrática. $O$ estudo refere que os dirigentes crêem que esta prática democrática é superior na sua própria instituição do que nas outras, o que aponta para a possibilidade de se estar perante a adesão formal e valorativa a um modelo e a um discurso que não corresponde totalmente à prática. Na prática, verifica-se que os presidentes das ONGs assumem grande parte do protagonismo em questões estratégicas como os acordos com a Segurança Social ou a contratação de funcionários, enquanto os técnicos apenas asseguram o funcionamento das valências. As populações-alvo raramente são consultadas e são remetidas a um papel passivo de meros destinatários dos serviços disponibilizados. Dois terços dos dirigentes inquiridos consideram mesmo que «os pobres» manifestam uma tendência pouco saudável para optar por soluções de cariz individualista em detrimento de opções colectivas. $O$ estudo conclui que os dirigentes das ONGs são geralmente oriundos de categorias relativamente escolarizadas e pertencem a classes sociais de estatuto elevado, ou então fazem parte do clero (cerca de 25\%), o que é explicado pela importância da Igreja na área social.

23 Perante este cenário, é pertinente considerar que as organizações voluntárias podem configurar relações de dominação dos seus líderes relativamente aos seus funcionários e beneficiários e em relação ao mundo exterior. Os potenciais riscos que este facto comporta são reconhecidos no plano institucional, ao nível comunitário. No Livro Branco sobre a Governação (2001), a Comissão Europeia assume que uma maior participação das organizações da sociedade civil nos mecanismos governativos implica uma maior responsabilidade e exige o respeito por princípios de «boa governação». Em consonância com esta preocupação, a Federação Europeia das Organizações Nacionais que trabalham com os Sem Abrigo (FEANTSA, 2007), uma umbrella organization sediada em Bruxelas 
dedicada especificamente à questão habitacional, defende a deslocalização e redistribuição do poder dentro das próprias organizações de forma a incluir os beneficiários, com o objectivo de promover a sua democraticidade, a orientação para a satisfação do consumidor e o desenvolvimento pessoal.

$\mathrm{Na}$ ausência de mecanismos compensadores como os acima propostos, selectividade do sistema político, que estabelece prioridades entre uma multiplicidade de conflitos e interesses, tem tendência para favorecer a supremacia dos grupos sociais mais privilegiados no sistema das organizações de solidariedade social e assim promover a sua sobre-representação ao nível da liderança (Siisiainen, 2000). Neste contexto, assume particular interesse a aplicação prática da teoria da acção de Bourdieu², que no contexto de um determinado campo social analisa o confronto entre actores com diversos capitais sociais, económicos e culturais, que lhes conferem um poder diferenciado que pode ser mobilizado na defesa dos seus interesses, o que passa pelo controlo dos princípios dominantes de legitimação social: se «uns» têm o poder para formar os «outros» para a cidadania, transmitindo-lhes valores e formas de estar e ser, encontram-se numa posição privilegiada para exercer esse controlo.

\section{Notas finais}

$\mathrm{Na}$ perspectiva teórica adoptada no presente artigo, o altruísmo é passível de questionamento e pode ser entendido enquanto um eufemismo na luta simbólica pelo poder, encontrando-se ao serviço dos interesses dos «mais poderosos». Daí a predilecção institucional pela mobilização em detrimento da participação, a qual, ao contrário da primeira, exige uma transferência efectiva de poder que coloca os "poderes instituídos» em risco:

$\mathrm{Eu}$ acho que o problema começa logo aí, começa na falta de capacidade que as organizações têm de promover a participação, o que até é compreensível porque pôr as pessoas a participar significa dar-lhes poder, e essa coisa de dar poder é um bocado complicado e eu não sei se as organizações estão preparadas para dar poder aos próprios, ou sequer se reconhecem que é útil"... "podemos entrar nuns desequilíbrios dos poderes entre assistidos e assistentes, isso implica mexer com as organizações de uma forma um bocadinho mais profunda do que aquilo que a gente possa imaginar, não é fácil"... "dentro das próprias ONGs, para nós reconhecermos que as próprias pessoas a quem se dá apoio podem funcionar como pares ao nível de todo o funcionamento da instituição, vamos pôr num patamar de igual para igual, estamos a dar não é só protagonismo, é dar o poder às pessoas de poderem participar e criar as condições para que isso possa acontecer, isso implica que as pessoas tenham que ter uma noção diferente do que é uma organização daquela que têm, que eu acho que é uma coisa muito hierarquizada, com vários patamares, desde os dirigentes aos técnicos, aos ditos grupos alvo, com quebras de comunicação onde é preciso mexer um bocadinho nesta estrutura e nestas práticas para que efectivamente as pessoas que são aquelas que são apoiadas poderem subir a um nível de participação efectiva, em termos do funcionamento das próprias instituições. Portanto acho que ainda há muita pedra por partir nesse domínio. (Excerto de entrevista a Isabel Baptista, perita independente para o PNAI, 2009)

Quando o altruísmo é possível, ou seja, quando a acção desinteressada é recompensada num contexto onde prevalece um habitus (disposições, reflexos e formas de comportamento socialmente adquiridos) a ela favorável, a reduzida participação dos destinatários dos serviços e políticas sociais na sua concepção, execução e avaliação, propicia uma noção de «bem» que não é a sua mas a daqueles que controlam as políticas e 
serviços ou neles trabalham: aquilo que os agentes políticos e os dirigentes e técnicos das organizações de solidariedade social consideram como sendo bom para os destinatários não coincide necessariamente com o que estes consideram que é bom para si próprios.

Este facto pode propiciar dinâmicas de manipulação mútuas: das organizações em relação aos beneficiários, ao tentarem encaminhá-los para acções e serviços que consideram benéficos ou que têm a responsabilidade de implementar mas que não são do interesse destes; e dos beneficiários em relação às organizações, ao adoptarem uma postura que acreditam corresponder àquilo que é percepcionado pelos técnicos como sendo adequado, mas que não corresponde à sua verdadeira forma de estar e ser.

O nível de envolvimento dos indivíduos nas políticas e serviços que lhes são dirigidos, entendido enquanto poder decisório e executivo, permite diferenciar entre trabalhar «com» ou «para» os beneficiários. Este facto vai influenciar a justiça das políticas e serviços ao determinar o acesso destes grupos sociais aos processos de decisão que os afectam. Quanto mais as políticas e serviços são concebidos e geridos pelos «outros», que possuem um capital social, económico e cultural diverso do próprio, menos adequados estão às suas reais necessidades e interesses, o que constitui uma porta aberta para a tentativa de manipulação e instrumentalização do sistema de apoio social por parte daqueles que dele usufruem - os próprios beneficiários. Este risco é tanto mais presente quanto a "violência simbólica» é ineficiente na sua função de convencimento e legitimação, ineficiência esta que poderá advir do facto de se basear numa «moral» distinta da dos seus destinatários, e logo não apreensível por eles: se os beneficiários não apreendem e adoptam as formas de estar e ser propostas pela retórica oficial, poderão utilizar os serviços sociais meramente numa perspectiva de usufruto imediato, sem qualquer intenção de aderir de facto às condutas socialmente valorizadas pelo Estado e seus parceiros.

No caso em análise, o equilíbrio de poderes verifi cado após a revolução de Abril deu lugar a um Estado fortalecido que nas suas margens encontra grupos desfavorecidos com quem frequentemente lida não directamente, mas de forma delegada, mediante as organizações de solidariedade social. Estas têm por função conceder apoio directo a estas populações, representar os seus interesses e formá-las para a «cidadania activa». No entanto, esta dinâmica altruísta de apoio social não é líquida e comporta inúmeras questões que se relacionam com os meandros do poder e com a luta simbólica pelos recursos que a ele dão acesso. Com esta consciência em mente, é pertinente considerar que se a legitimidade e a efectividade do sistema político democrático são conseguidas mediante uma justiça ilusória, que não promove de facto o acesso dos cidadãos em situação de maior vulnerabilidade aos mecanismos governativos que os afectam, a sua natureza democrática não poderá ser mais do que aparente. Temos então uma democracia que não passa de um eufemismo na luta simbólica pelo poder, na qual os actores envolvidos se dedicam a um «jogo de espelhos» que substitui a realidade pela sua aparência. 


\section{BIBLIOGRAPHY}

BAÍA, João (2008), “Bairro da Relvinha (1974-1976): de barracas a condições condignas”, apresentado no VI Congresso Português de Sociologia: Mundos Sociais - saberes e práticas. Lisboa: APS e FCSH-UNL, 25-28 de Junho.

BOURDIEU, Pierre (2008), “The forms of capital”, in W. Biggart (Ed.), Readings in Economic Sociology. Oxford: Blackwell Publishers Ltd.

BOURDIEU, Pierre (1991), In Other Words: Essays Toward a Reflexive Sociology. Cambridge: Polity Press.

BUREAU Internacional do Trabalho (2003), A luta contra a pobreza e a exclusão social em Portugal. Genebra: Experiências do programa nacional de luta contra a pobreza, Programa Estratégias e Técnicas contra a Exclusão Social e a Pobreza.

CACHADO, Rita (2009), "Habitação social nas últimas décadas”, in Vírus - Cidades Invisíveis. nำ7, novembro/Dezembro [http://www.esquerda.net/virus/media/virus7txt.pdf] (12/01/2012)

CAPUCHA, Luís (1995) (coord.), “ONGs de solidariedade social: práticas e disposições”. In Cadernos REAPN, Porto: REAPN.

CEREZALES, Diego Palacios (2003), o Poder caiu na rua - crise de Estado e acções colectivas na revolução portuguesa. Lisboa: Imprensa de Ciências Sociais.

COLLIER, David e MAHON, James (1993) “Conceptual “Stretching” Revisited: Adapting Categories in Comparative Analysis", in The American Political Science Review, Vol.87, Issue 4, Washington: American Political Science Association, pp.845-855.

COMISSÃO Europeia (2001), Livro Branco: Governação Europeia, COM (2001) 428 final de 25/07/2001. CONSELHO Nacional do SAAL (1976), Livro Branco do SAAL 1974-1976. Porto: Membros efectivos do VI Conselho Nacional do SAAL, novembro de 1976.

FEANTSA (2007), Participation toolkit - redistributing the power. Bruxelas: FEANTSA.

FERREIRA, António (1994), “Habitação social: lições e prevenções para o PER”, in Sociedade e Território 20 - As pessoas não são coisas que se ponham em gavetas. Porto: Edições Afrontamento, pp. 8-10.

FERREIRA, António (1993), Livro Branco sobre a política de habitação em Portugal, Porto: Edições Afrontamento.

FERREIRA, António (1988), "Política(s) de habitação em Portugal”, in Sociedade Território, 6: 54-62.

FERREIRA, Vítor (1975), “Movimentos Sociais Urbanos e Intervenção Política”. in Cidade em Questão, nº 4. Porto: Afrontamento.

GROS, Marielle Christine (1994), “«Pequena» História do Alojamento Social em Portugal”, in Sociedade e Território, n²0. Porto: Edições Afrontamento, pp.80-90.

GUERRA, Isabel (1994), “As pessoas não são coisas que se ponham em gavetas”, in Sociedade e Território n²0 - As pessoas não são coisas que se metam em gavetas. Porto: Edições Afrontamento, pp.11-16. 
MCADAM, Doug et al. (2009), "Para mapear o confronto politico", in Lua Nova. nº 76, São Paulo: pp. 11-48.

PORTAS, Nuno (1986), “O Processo SAAL: Entre o Estado e o Poder Local”. in Revista Crítica de Ciências Sociais. no 18/19/20, Coimbra: CES, pp. 635-644.

QUEIRÓS, João (2007), "Estratégias e discursos políticos em torno da reabilitação de centros urbanos - considerações exploratórias a partir do caso do Porto”. in Sociologia Problemas e Práticas. n55, Lisboa: CIES, pp.91-116.

RODRIGUES, C. (2009), O papel consultivo das ONGs de solidariedade social na Estratégia Nacional de Inclusão Social. Dissertação de Mestrado, Lisboa: FCSH-UNL.

RODRIGUES, Maria (1999), Pelo Direito à Cidade: O Movimento de Moradores do Porto (1974/76), Porto: Campo das Letras.

SANTOS, Boaventura Sousa (1984), "A Crise e a Reconstituição do Estado em Portugal (1974-1984)”, in Revista Crítica de Ciências Sociais. no14, Coimbra: CES, pp. 7-29.

SARTORI, G. (2009)3, "Concept misformation in comparative politics". in D. Collier e J. Gerring (Eds.), Concepts and Method in Social Science - The tradition of Giovanni Sartori. Nova Iorque e Londres: Routeledge, pp.13-44.

SIISIÄINEN, M. (2000), “Two Concepts of Social Capital: Bourdieu vs. Putnam”. apresentado na $4^{\underline{a}}$ Conferência Internacional ISTR The Third Sector: for what and for whom?. Dublin: Trinity College, 5-8 de julho.

VILAÇA, Helena (1994), Associativismo e movimentos sociais - modalidades de participação. Porto: Faculdade de Letras.

\section{NOTES}

1. As entrevistas citadas derivam do trabalho de campo efectuado para a dissertação de mestrado da autora (Rodrigues, 2009), bem como de momentos posteriores de investigação empírica que contribuíram nomeadamente, para a elaboração do seu projecto de doutoramento em ciência política.

2. Tivemos em atenção o contexto específico a que os conceitos referidos se aplicam, procurando reter as virtudes da «viagem conceptual» sem resvalar para os riscos da sua «distorção» (Collier e Mahon,1993).

\section{ABSTRACTS}

Assumindo a área da habitação social como um campo social onde as diversas formas de capital constituem os factores chave que definem as possibilidades dos actores triunfarem no jogo do poder, a reprodução das estruturas de dominação produzidas pelo conflito entre grupos é analisada nos programas de realojamento implementados desde a revolução de abril até à actualidade. O papel dos moradores, das autarquias e das organizações de solidariedade social é condicionado por esta dinâmica conflitual, permitindo equacionar que níveis e tipos de 
envolvimento cívico serão mais adequados para a gestão de problemas centrais para a qualidade da governação democrática contemporânea, como a justiça, a legitimidade e a efectividade. Paralelamente, é equacionado o real alcance do altruísmo, enquanto princípio legitimador da intervenção social.

By understanding social housing as a political field in which several forms of capital constitute the main factors that define the actors' possibilities of succeeding in the game of power, the production and reproduction of the dominance structures that have resulted from the conflict between groups has been analysed in the social housing programmes which have been implemented in Portugal, since the 1974 revolution up to now. The positioning of the inhabitants, the local and national powers and the social NGOs in the programmes, which has been conditioned by these conflictive dynamics, allows for us to ask which levels and types of involvement are more suitable for the management of central problems of contemporary democratic governance such as justice, legitimacy and effectiveness. We also question the reach of altruism as a legitimating feature for social intervention.

Considérant le secteur de logement social comme un domaine social dans lequel plusieurs formes de capital constituent les facteurs principaux qui défi nissent les possibilités des acteurs à arriver au jeu de pouvoir, la reproduction des structures de prédominance qui résultent du conflit entre les groupes est analysée dans les programmes de logement sociaux exécuté de la révolution d'avril jusqu'à présent. Le rôle des habitants, des municipalités et des organismes de bienfaisance dans les programmes, qui est conditionné par cette dynamique de conflit, nous permet de questionner quels niveaux et quels types d'engagement seront les plus appropriés à la gestion de problèmes centraux de la gouvernance démocratique contemporaine comme la justice, la légitimité et l'effi cacité. Nous contestons également la portée de l'altruisme, en tant que principe de légitimation de l'intervention sociale.

\section{INDEX}

Mots-clés: programmes de relogement, démocratie participative, exclusion sociale, théorie de l'action, altruisme

Keywords: housing programmes, participatory democracy, social exclusion, action theory, altruism

Palavras-chave: programas de realojamento, democracia participativa, exclusão social, teoria da acção, altruísmo

\section{AUTHOR}

\section{CAMILA RODRIGUES}

Investigadora do Observatório Político e do CESNOVA, camilapombeiro@gmail.com 